\title{
IMPLEMENTASI SISTEM PENGOLAHAN DATA PASIEN (SIPEDAS) PADA UPT PUSKESMAS MANDOMAI
}

\author{
M. Haris Qamaruzzaman ${ }^{1}$, Sutami $^{2}$, Candra Kurniawan ${ }^{3}$, M. Ziaurrahman ${ }^{4}$, Sam'ani $^{* 5}$ \\ ${ }^{1,2.3 .4}$ Universitas Muhammadiyah Palangkaraya \\ ${ }^{5}$ STMIK Palangkaraya \\ Email : $\underline{\text { sam.stmikplk@gmail.com }}$
}

\begin{abstract}
Abstrak
UPT Puskesmas Mandomai setiap harinya melayani masyarakat setempat yang berobat dan melakukan pelaporan data pasien setiap bulannya, sementara dalam proses pengolahan data tersebut sudah dilakukan secara terkomputerisasi, namun hanya sebatas menggunakan aplikasi Microsoft Office (Word \& Excell) sehingga belum optimalnya pengolahan data menyebabkan sulitnya mencari informasi tentang data pasien dan pembuatan laporan yang belum memadai. Oleh karena itu perlu diimplementasikan/diterapkan sistem komputerisasi yang bisa mendukung, membantu dan mempermudah serta mempercepat untuk pelayanan dan pengolahan data pasien yang dalam hal ini yaitu Aplikasi Sistem Pengolahan Data Pasien (SIPEDAS). Metode pelaksanaan kegiatan yaitu pengaturan (setting) komputer, implementasi sistem aplikasi, dan sosialisasi aplikasi. Hasil dari kegiatan ini adalah diterapkan dan diimplementasikannya aplikasi SIPEDAS pada UPT Puskesmas Mandomai.
\end{abstract}

Kata Kunci : Aplikasi SIPEDAS, Implementasi, Puskesmas

\begin{abstract}
UPT Puskesmas Mandomai serves the local community for treatment every day and reports patient data every month while processing the data has been done computerized, but only limited to using Microsoft Office applications (Word \& Excel) so that the data processing is not optimal, causing it to be challenging to find information about patient data and making reports that are not adequate. Therefore, it is necessary to implement/implement a computerized system that can support, assist and simplify and speed up the service and processing of patient data, which is the Patient Data Processing System Application (SIPEDAS). Implementing the activity is setting the computer, implementing the application system, and socializing the application. The result of this activity is the implementation of the SIPEDAS application at UPT Puskesmas Mandomai.
\end{abstract}

Keywords : SIPEDAS App, Implementation. Puskesmas 


\section{PENDAHULUAN}

Dalam era komputerisasi saat ini pengolahan data dan penyebaran informasi dirasakan kurang efektif dan efisien apabila sumber itu dalam bentuk kertas yang sifatnya statis atau mengandalkan memori seseorang sebagai media penyimpanannya (Sam'ani et al., 2020). Seriring perkembangannya, penggunaan Internet tidak dapat dipungkiri memberikan kemudahan, optimasi dan efektifitas dikehidupan masyarakat (Hakim et al., 2021). Begitu pula dengan proses pengolahan data Pasien di UPT Puskesmas Mandomai di Kecamatan Kapuas Barat Kabupaten Kapuas Kalimantan Tengah.

Walaupun sebagian sudah dilakukan secara terkomputerisasi, namun hanya sebatas menggunakan aplikasi Microsoft Office (Word \& Excell) sehingga belum optimalnya pengolahan data menyebabkan sulitnya mencari informasi tentang data pasien dan pembuatan laporan yang belum memadai. Disertai juga dengan tidak semua Puskesmas memiliki Sumber Daya Manusia (SDM) yang dapat menggunakan teknologi tersebut (Oktaviani et al., 2021). Sehingga menimbulkan berbagai permasalahan seperti kesulitan mencari data pasien yang terkadang data yang sudah begitu lama bisa hilang, dan permasalahan lainnya yang berhubungan dengan prosedur penyimpanan data. Hal ini akan menyulitkan bidang sarana dalam memberikan laporan kepada pimpinan maupun pihak lain yang memerlukan data.

Oleh karena itu perlu diimplementasikan/diterapkan sistem komputerisasi yang bisa mendukung, membantu dan mempermudah serta mempercepat untuk pelayanan dan pengolahan data pasien yang dalam hal ini yaitu Aplikasi Sistem Pengolahan Data Pasien (SIPEDAS).

Aplikasi SIPEDAS yang akan diimplemetasikan pada UPT Puskesmas Mandomai ini merupakan sistem aplikasi yang bebas/gratis tidak berbayar dengan berbagai fitur yang tidak kalah dengan aplikasi yang berbayar.

Dengan mengamati permasalahan mitra tersebut maka kegiatan implementasi sistem aplikasi ini ditujukan agar supaya mendukung, membantu dan mempermudah serta mempercepat pelayanan dan pengolahan data pasien oleh pihak UPT Puskesmas Mandomai.

\section{METODE}

Kegiatan Pengabdian masyarakat ini dilaksanakan oleh Universitas Muhammadiyah Palangkaraya melalui Lembaga Penelitian dan Pengabdian Kepada Masyarakat (LP2M) 
dengan menugaskan dosen program studi Ilmu Komputer yang berada dibawah naungan Fakultas Teknik dan Informatika (FTI) (Sam'ani et al., 2019) yang tahun ini bertempat di UPT Puskesmas Mandomai yang beralamat di Jalan Bakti Husada Kecamatan Kapuas Barat Kabupaten Kapuas Kalimantan Tengah.

Kegiatan ini dilaksanakan pada bulan Juni sampai Juli 2021. Tabel 1 berikut adalah jadwal kegiatan pengabdian ini :

Tabel 1. Metode Kegiatan

\begin{tabular}{|l|l|l|}
\hline \multicolumn{1}{|c|}{ Kegiatan } & \multicolumn{1}{|c|}{ Keterangan } & \multicolumn{1}{c|}{ Waktu } \\
\hline Kegsiapan Sebelum & $\begin{array}{l}\text { Mempersiakan segala keperluan } \\
\text { kegiatan dan Survey Lokasi }\end{array}$ & Juni 2021 \\
\hline Pelaksanaan Kegiatan & $\begin{array}{l}\text { 1. Pengaturan (Setting) Jaringan } \\
\text { 2. Implementasi dan Instalasi } \\
\text { Aplikasi } \\
\text { 3. Sosialisasi aplikasi kepada pihak } \\
\text { administrasi, operator dan } \\
\text { pimpinan Puskesmas Mandomai }\end{array}$ & $\begin{array}{l}\text { Minggu I Juli } \\
\text { Kegiatan }\end{array}$ \\
\hline Sesudah Pelaksanaan & $\begin{array}{l}\text { 1. Evaluasi Hasil Pelaksanaan } \\
\text { Kegiatan }\end{array}$ & $\begin{array}{l}\text { Minggu II - } \\
\text { IV Juli 2021 }\end{array}$ \\
& $\begin{array}{l}\text { 2. Pembuatan Laporan kegiatan } \\
\text { 3. Dokumentasi dan artikel jurnal }\end{array}$ & \\
\hline
\end{tabular}

\section{HASIL DAN PEMBAHASAN}

Pelaksanaan kegiatan pengabdian masyarakat berupa implementasi, instalasi, dan pelatihan aplikasi SIPEDAS ini yaitu :

a. Proses implementasi dan instalasi aplikasi SIPEDAS pada PC layanan administrasi dan operator serta pimpinan UPT Puskesmas Mandomai telah berhasil dilaksanakan dengan baik dan lancar.

b. Sosialisasi/Pelatihan penggunaan aplikasi SIPEDAS kepada bagian administrasi dan operator serta pimpinan UPT Puskesmas Mandomai telah berhasil dipahami, dimengerti dan dioperasikan dengan lancar. 
c. Dengan digunakannya aplikasi SIPEDAS ini diharapkan bisa mendukung, membantu dan mempermudah serta mempercepat untuk pelayanan dan pengolahan data pasien UPT Puskesmas Mandomai sehingga dapat memberikan kuantitas dan kualitas layanan yang lebih cepat, tepat dan efesien.

Adapun pelaksanaan kegiatan dapat dilihat pada gambar 1 dan 2 berikut :
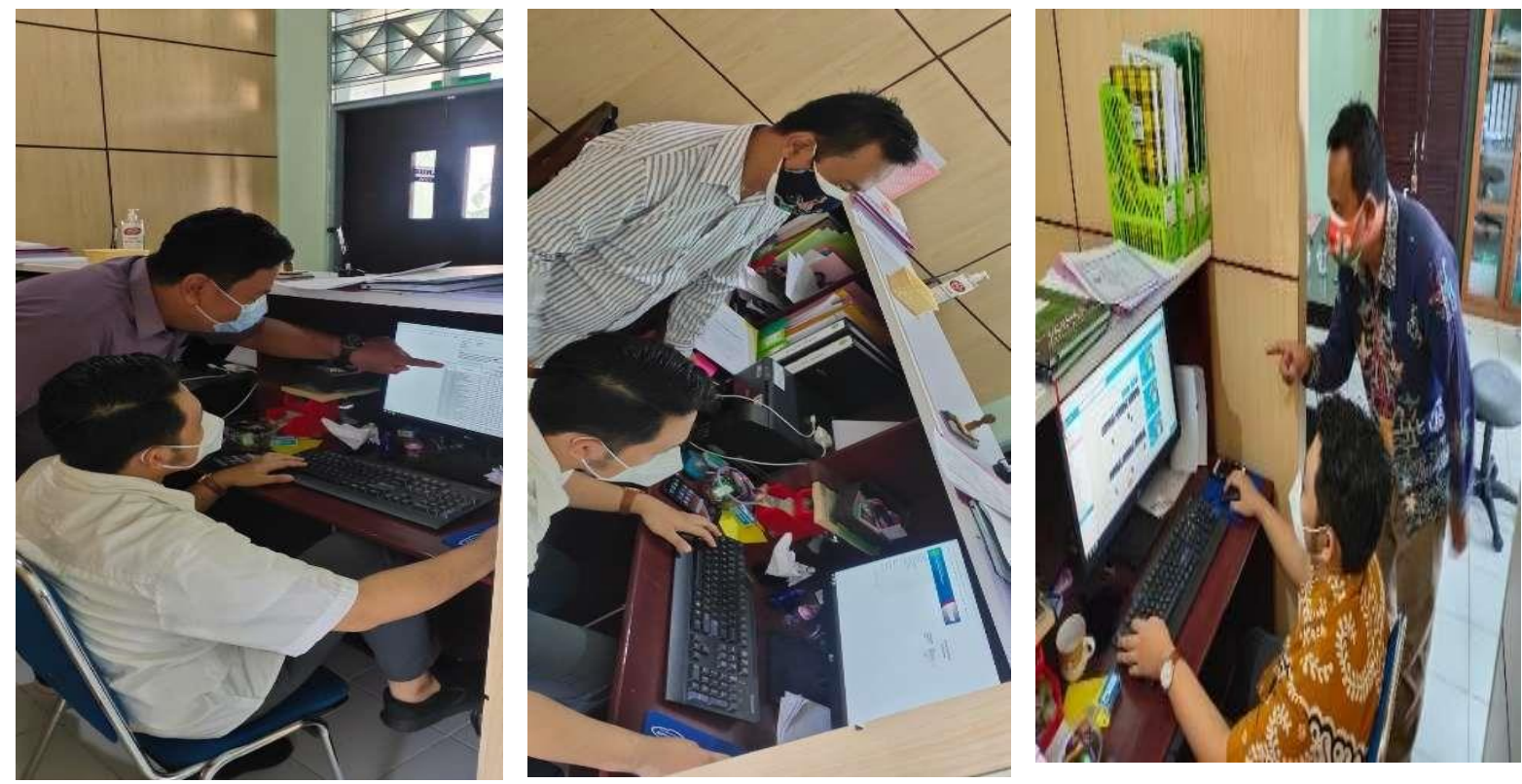

Gambar 1. Sosialisasi/Pelatihan penggunaan aplikasi SIPEDAS di UPT Puskesmas Mandomai

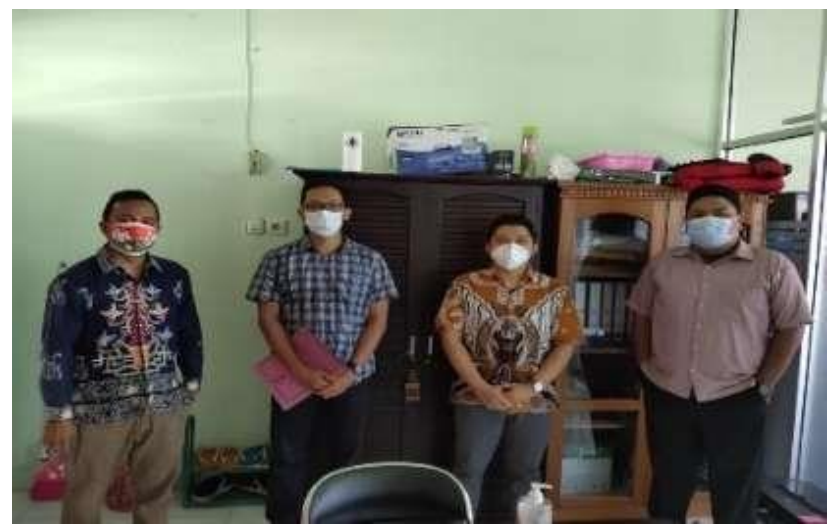

Gambar 2. Foto bersama setelah kegiatan di UPT Puskesmas Mandomai Aplikasi SIPEDAS ini terdiri dari beberapa menu utama seperti terlihat pada gambar 3 berikut : 


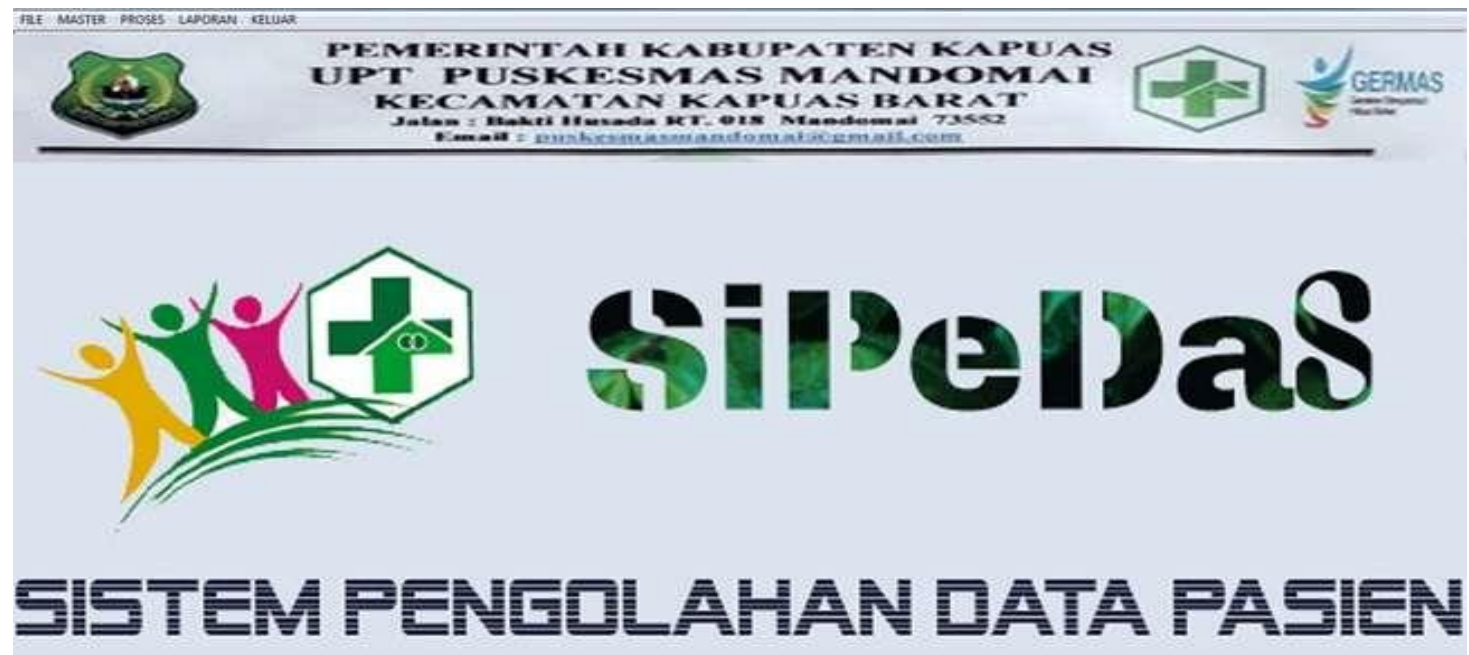

Gambar 3. Tampilan Menu Utama SIPEDAS

a. Menu File untuk masuk ke aplikasi SIPEDAS menggunakan nama pengguna dan sandi yang telah didaftarkan sebelumnya.
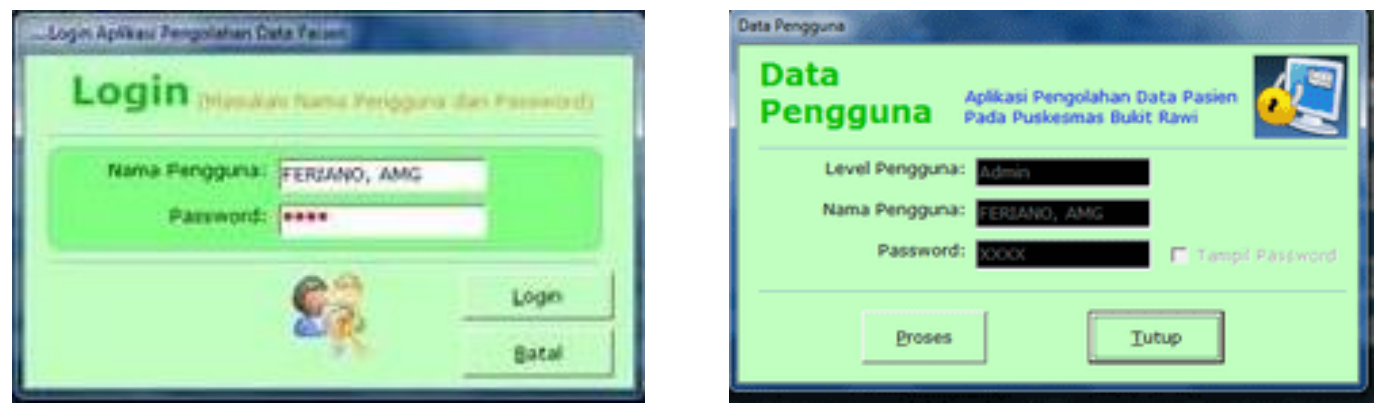

Gambar 4. Tampilan Form Login Awal dan tambah pengguna

b. Menu Master. Didalam menu master ini terdapat beberapa submenu yaitu : Sub Menu Data Obat, Sub Menu Data Dokter dan Sub Menu Data Pasien 

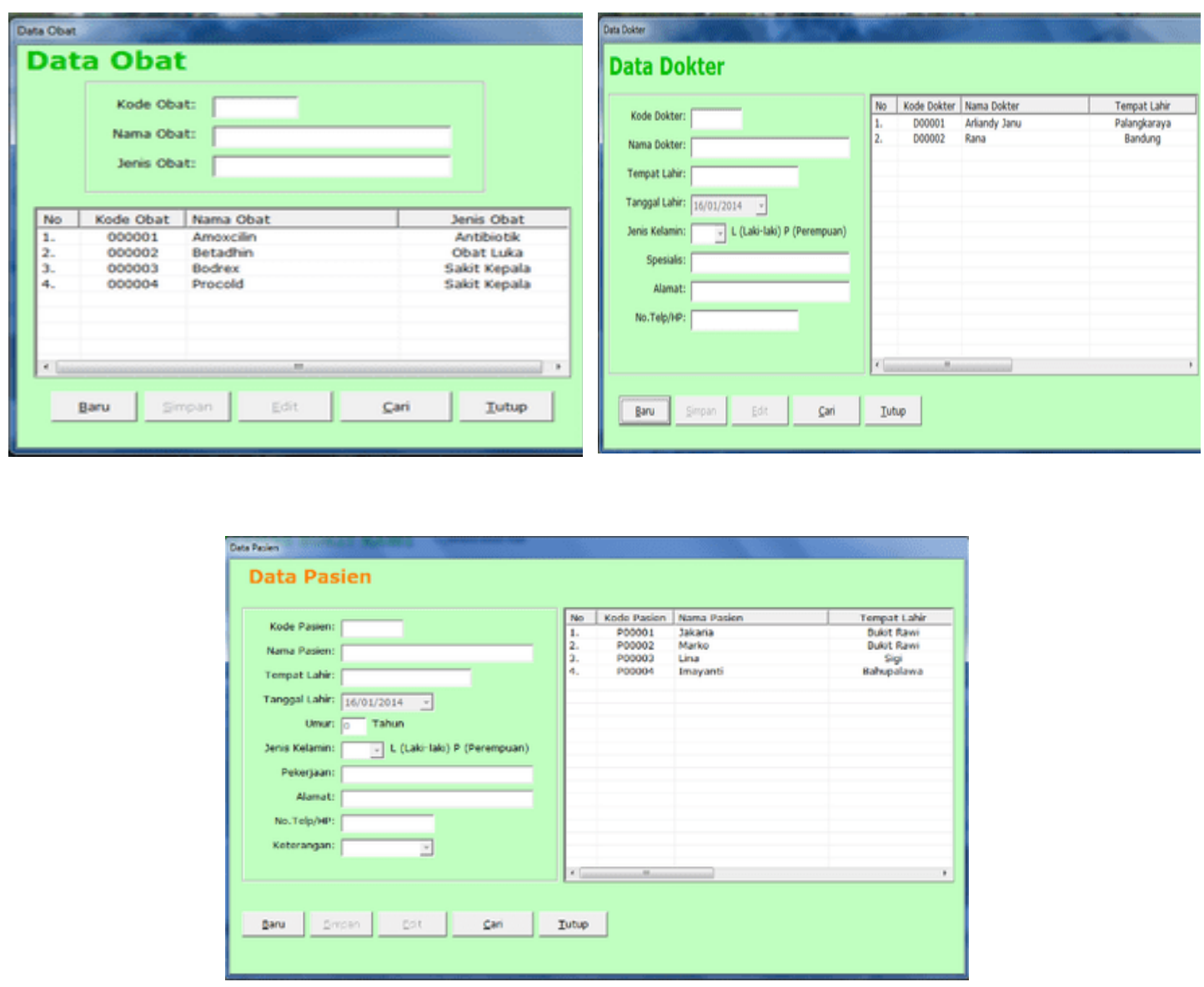

Gambar 5. Tampilan Sub Menu Data Obat, Sub Menu Data Dokter dan Sub Menu Data Pasien

c. Menu Proses. Pada menu ini terdiri dari 1 submenu yaitu : Sub Menu Pemeriksaan yang berisi juga Tombol Cetak untuk mencetak data pasien untuk di bawa pada saat mengambil resep yang diberikan oleh dokter 


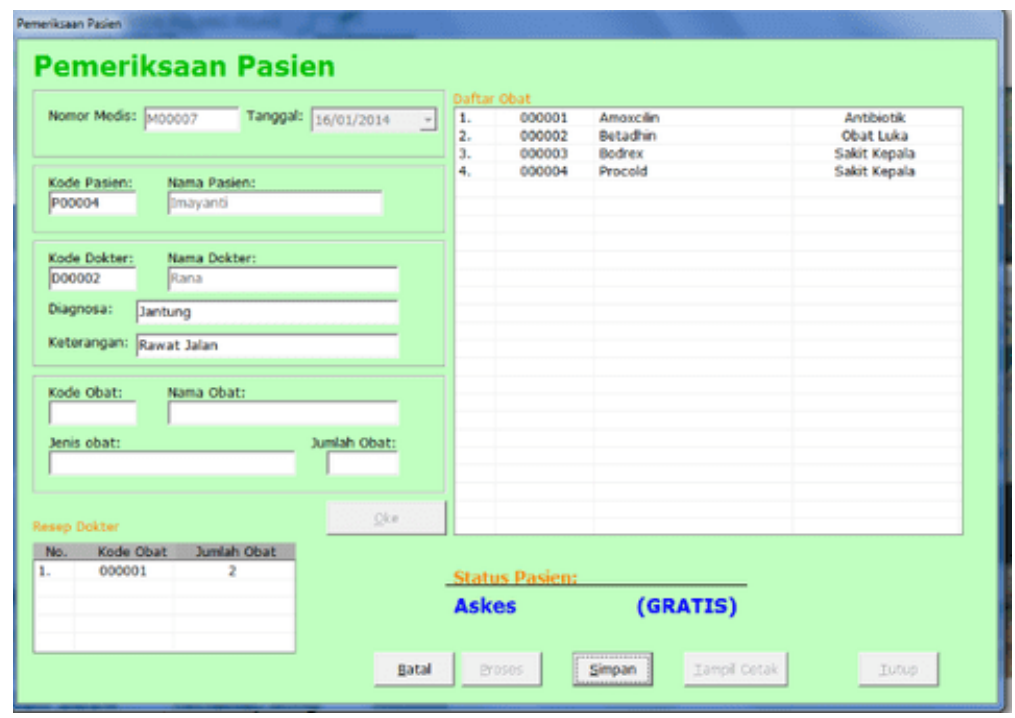

Gambar 6. Tampilan Sub Menu Pemeriksaan yang berisi juga Tombol Cetak

d. Menu Laporan. Pada menu ini terdiri dari beberapa submenu yaitu : Sub Menu Laporan Data Obat, Sub Menu Laporan Data Dokter, Sub Menu Laporan Data Pasien, Kartu Berobat, dan Laporan Pemeriksaan Pasien.
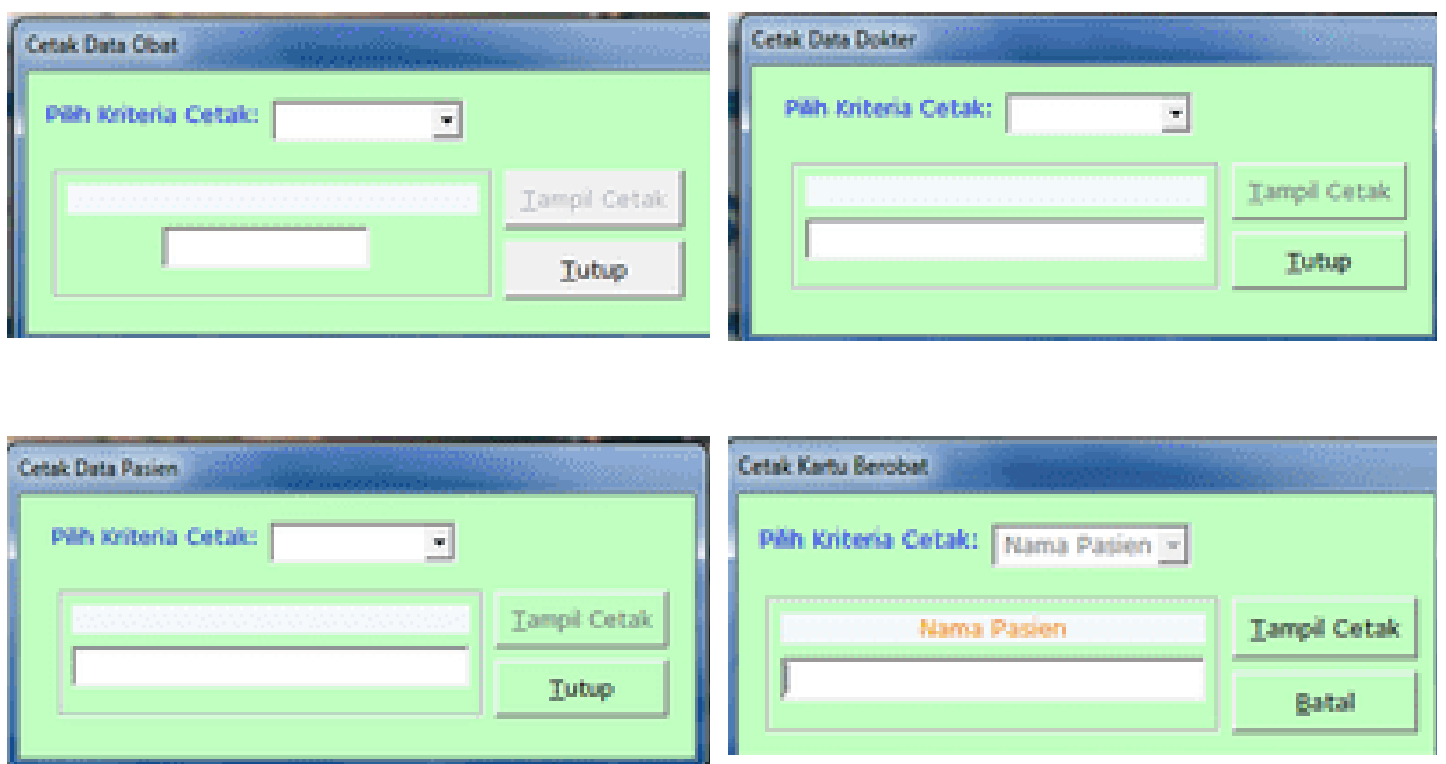

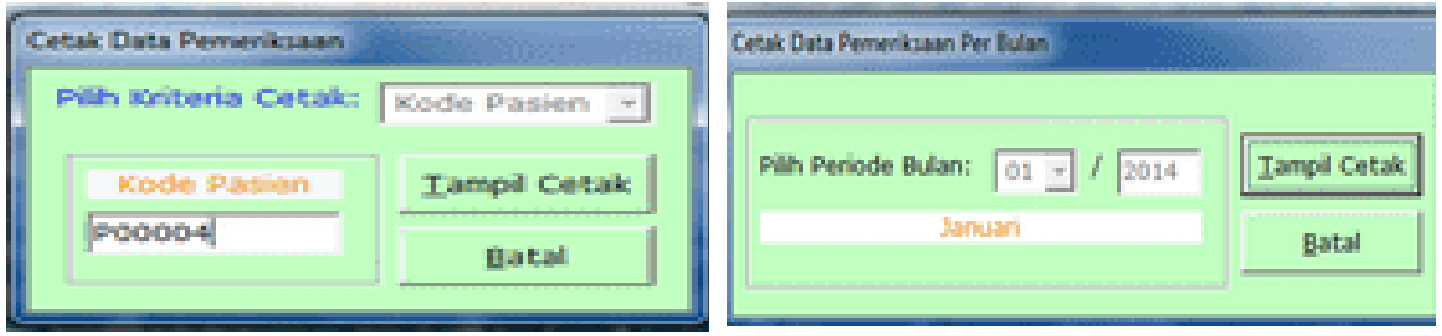

Gambar 7. Tampilan Sub Menu Laporan Data Obat, Sub Menu Laporan Data Dokter,

Sub Menu Laporan Data Pasien, Kartu Berobat, dan Laporan Pemeriksaan Pasien

e. Menu Keluar dari aplikasi

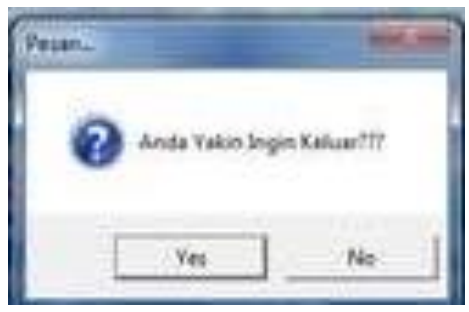

Gambar 8. Menu Keluar dari aplikasi

\section{KESIMPULAN}

Kesimpulan dari hasil kegiatan pengabdian pada masyarakat yang dilaksanakan bulan Juni - Juli 2021 ini yaitu Tim pelaksana telah berhasil mengimplementasikan, menerapkan dan mensosialisasikan sebuah sistem aplikasi SIPEDAS pada bagian administrasi dan operator serta pimpinan UPT Puskesmas Mandomai. Dengan adanya aplikasi SIPEDAS ini diharapkan dapat dipergunakan dan diterapkan guna mendukung, membantu dan mempermudah serta mempercepat pelayanan dan pengolahan data pasien oleh pihak UPT Puskesmas Mandomai.

\section{UCAPAN TERIMA KASIH}

Tim pelaksana kegiatan pengmas ini menyampaikan terima kasih kepada beberapa pihak, yaitu : Universitas Muhammadiyah Palangka Raya melalui Lembaga Penelitian dan Pengabdian Kepada Masyarakat (LP2M) yang telah mendanai program ini. Kemudian pimpinan dan seluruh staf/karyawan UPT Puskesmas Mandomai yang telah menyediakan tempat dan waktu selama kegiatan ini berlangsung hingga selesai. 


\section{DAFTAR PUSTAKA}

Hakim, T. D., Amelia, V., \& Monika, W. (2021). PKM Penyuluhan Internet Sehat Di SMK Telkom Pekanbaru. Jubaedah: Jurnal Pengabdian Dan Edukasi Sekolah (Indonesian Journal of Community Services and School Education), 1(1), 51-59. https://doi.org/10.46306/jub.v1i1.10

Oktaviani, I., Rini, I. A., Mia Ulfah, M., \& Andriana, A. D. (2021). Pengenalan Media Pembelajaran Daring Berbasis STEM Untuk Guru IPA Di SMAN 9 Bandar Lampung. Jubaedah: Jurnal Pengabdian Dan Edukasi Sekolah (Indonesian Journal of Community Services and School Education), 1(1), 77-88. https://doi.org/10.46306/jub.v1i1.16

Sam'ani, Qamaruzzaman, M. H., \& Sutami. (2020). Implementasi Sistem Pengawasan Dan Pengendalian Serta Penggunaan Komputer Pada Laboratorium Komputer SMK Isen Mulang Palangkaraya. MARTABE: Jurnal Pengabdian Masyarakat, 3(2), 303-307. https://doi.org/DOI : 10.31604/jpm.v3i2.303-307

Sam'ani, Sutami, \& Qamaruzzaman, M. H. (2019). Implementasi Aplikasi Pembelajaran Untuk Anak Berbasis Android. Martabe: Jurnal Pengabdian Kepada Masyarakat, 2(2), 106. https://doi.org/10.31604/jpm.v2i2.106-110 